\title{
Problem-Solving Strategies Used by Eight Grade Students
}

\author{
Ratnasari Ratnasari ${ }^{1 *}$ (1), Desyarti Safarini TLS ${ }^{1 * \star}$ (1)
}

${ }^{1}$ Sampoerna University, INDONESIA

*Corresponding Author: ratnasari.ratnasari@my.sampoernauniversity.ac.id

**Corresponding Author: desyarti.safarini@sampoernauniversity.ac.id

Citation: Ratnasari, R., \& Safarini TLS, D. (2020). Problem-Solving Strategies Used by Eight Grade Students. Contemporary Mathematics and Science Education, 1(2), ep20008. https://doi.org/10.30935/conmaths /8497

\begin{abstract}
This qualitative research aims to describe the common strategies used by 8-th grade students to get a solution for two non-routine problems. The research participants were twenty 8th graders in one of private middle schools in Jakarta. Six participants were selected for interview sesion. The researcher gave a test, which consists of two nonroutine problems about algebra and interviews the subjects to gain more information. The result showed that there were three common strategies used by the participants to solve problem 1, which act it out, draw a model, and guess and check. Moreover, it was found that the guess nad check is the only strategy used by the participants to answer problem 2.
\end{abstract}

Keywords: eight grade students, non-routine problems, problem-solving strategies

Received: 1 Jun. 2020 Accepted: 12 Jul. 2020

\section{INTRODUCTION}

In today's era, one of the abilities that can help individuals to be ready for their future career is problem-solving. The reason is that in the real situations, people are facing many complex task that demand them to be creative and using a multiple strategies to address the solution and complete all tasks. Moreover, Common Core State Standards and Partnership for $21^{\text {st }}$ century skills mentioned that education need to focus on both core academic subject mastery and $21^{\text {st }}$ century skills development. Then, problem-solving is not only one of the Process Standards in NCTM's Principles and Standards for School Mathematics but also become the main aspect of mathematics teaching and learning process. The reason is that problem-solving is a part of all content areas. Also, problem-solving activities and mathematical learning cannot be separated, because in learning mathematics, it involves solving the problems (Nurkaeti, 2018).

Unfortunately, according to the PISA (Program for International Students Assessment) result in 2015, it shows that Indonesian students were not able to achieve an average score in the mathematics subject (OECD, 2016). Other than that, Kurniati and Anizar (2017) conducted a study regarding students' problem-solving ability in solving PISA problems. Based on data analysis, it showed that the students struggle to solve the given PISA problems, and they have a low performance in mathematical problem-solving ability. For example, the students find it challenging to build a connection between mathematical concepts, to organize and carry out their plan, and to check the correctness of the steps and answers.
Considering the importance of problem-solving ability, Indonesia should give more attention to developing students' problem-solving ability which relatively low. Therefore, there are needs strong efforts from government, schools, teachers, and other parties on improving the Indonesian students' problem-solving ability in mathematics. There is a private middle school in Jakarta uses Cambridge IGCSE (International General Certificate of Secondary Education) curriculum that requires students to implement a combination of mathematical skills and techniques in problem-solving. In this school, one of the 8thgrade classes participates actively during mathematics learning activities. For example, they proactively respond to the teacher's questions, solve the given problems, and ask questions to the teacher. Interestingly, when the students are solving the given problem, they rarely write the steps or show their work on how to solve the given problems. Instead, only write the final solution. In order to know their problem-solving strategies used, gathering the information their strategies used in solving non-routine problems is needed. Thus, this study aims to investigate the common strategies used by $8^{\text {th }}$ grade students to get a solution for two non-routine problems.

The researcher expects that this study can contribute to be a reference regarding students' problem-solving strategies in mathematical problem-solving. Moreover, the study is expected to be beneficial for teachers in schools to give information regarding their students' problem-solving strategies in solving non-routine problems. Besides teachers, this study might be helpful for other researchers and people who are interested in mathematical problem-solving. The research question that would be addressed in this study is what are the common strategies used by $8^{\text {th }}$ grade students to solve the two nonroutine problems? 
Table 1. Aspects of Polya's Problem-Solving Strategy

\begin{tabular}{|c|c|}
\hline $\begin{array}{l}\text { Phase or Aspect of } \\
\text { Problem-Solving }\end{array}$ & Indicators \\
\hline $\begin{array}{l}\text { Understanding the } \\
\text { problem }\end{array}$ & $\begin{array}{l}\text { - Identify aspects are known on the problem } \\
\text { - Mention the information based on the problem } \\
\text { - Connect the problem with another topics on } \\
\text { mathematics }\end{array}$ \\
\hline Devising a plan & $\begin{array}{l}\text { - Make a mathematical form based on the problem } \\
\text { - Show mathematical concept that would be used to } \\
\text { solve problem }\end{array}$ \\
\hline Carrying out the plan & $\begin{array}{l}\text { - Analyze the process of problem-solving based on a } \\
\text { plan }\end{array}$ \\
\hline Looking back & - Check the accuracy of answer with the questions. \\
\hline
\end{tabular}

\section{Polya's Problem-Solving Strategy}

According to Kaur (2008) problem-solving is a complex process where an individual is required to relate prior experiences, knowledge, understanding, and intuition to fulfill the demands of a new situation. Problem-solving tasks usually involve non-routine problems in which a problem solver has a no-readily available procedure to get a solution. It is the same as what NCTM in 1991 mentioned that type of problem that can offer opportunities for the students to support and extend what students know and encourage mathematics learning is the worthwhile or non-routine problems (Kaur, 2008). Moreover, the worthwhile problems should involve students in exploring essential mathematical ideas and ways of thinking towards learning goals.

Based on NCTM there are ten criteria of worthwhile or nonroutine problems (Cai \& Lester, 2010) as follows:

1. The problem has essential, useful mathematics embedded in it.

2. The problem requires higher-level thinking and problemsolving.

3. The problem is contributing to the conceptual development of students.

4. The problem creates an opportunity for the teacher on how to assess students learning and where they are experiencing difficulty.

5. The problem can be solved by using different ways or strategies.

6. The problem has more than one solution or allows students to make different decision or position when solving the problem.

7. The problem encourages student's engagement and discourse.

8. The problem relates to other essential mathematical ideas.

9. The problem promotes the use of mathematics.

10. The problem allows students to practice essential skills.

It is hard for the teacher to suppose that every chosen problem should fall in all criteria. The teacher can focus on some criteria by considering the instructional goals. These ten criteria are a guideline for a teacher to decide which problem can be an essential aspect of his or her instruction.

To determine students' problem-solving ability, George Polya or also known as the father of problem solving, claimed that there are four phases in the problem-solving process. The phases are: understanding the problem, devising a plan, carrying out the plan, and looking back. Polya also mentioned those four phases in his book "How to solve it" in 1957. Table 1 shows those four phases in Polya's problem-solving strategies included the indicators in each phase.
In problem-solving, heuristics and strategies represent specific methods and procedures used in the process of getting a solution. Then, there are many ways to get the solution in problem-solving. Kaur (2008) mentioned some common problem-solving heuristics might be used by the students when solving the problem are:

1. Act it out: In this heuristics, problem solvers are required to be active and walk through the problem.

2. Draw a diagram or draw a model: This heuristic can be used by problem solvers to illustrate the problem. It is an effective method for problem solvers to describe and solve the problem.

3. Guess and check: This heuristic is a simple way to get a solution. However, this heuristic is not always being a good way to get a solution except the guess leads to a better guess that derives a solution. Thus, there are two types of guess and check. The first is systematically guess and check. The problem solver can get the solution after having a few iterations. The second type of guess and check is unsystematic guess and check. This unsystematic way maybe not resulting in the correct solution.

4. Make a systematic list: A systematic list is a list produced by listing all the given information based on problems and possibilities systematically. This heuristic can be a guideline for the problem solver to attain the solution.

5. Restate the problem: This heuristic sometimes can help define the problem. Then restating the problem into the simplest one can help problem solver to understand and solve the problem.

6. Use an equation: When solving the problem, the students or problem-solver may utilize their knowledge of algebra to get a solution. The problem solvers use an equation or system of equation, which is in algebra to solve the problem.

7. Work backward: In work backward heuristic, problem-solvers start to solve the problem from an endpoint of a condition to where it is happening. Moreover, the problem-solvers need to keep the way of information and to systematize it in a meaningful way.

\section{METHODOLOGY}

To address the objective of the study, a qualitative descriptive was used as research method to present the event summaries that experienced by a group of people comprehensively. In this case, it is the description and interpretation of students' problem-solving strategies to get a solution for two non-routine problems. The researcher interpreted and described the event based on fact, and data analysis was presented descriptively. As cited by Clinton and Vickie (2012) Sandelowski stated that qualitative descriptive method is the least theoretical approach based on naturalistic investigations and views of something in its natural state.

The study involved twenty participants who are $8^{\text {th }}$ grade students in a private middle school in Jakarta. Based on International General Certificate of Secondary Education (IGCSE) curriculum, $8^{\text {th }}$ grade students already learned about linear equation one variable and simultaneous equation (CIE, 2016). Thus, it is possible for the researcher to given non-routine problems related to those two topics. Then, the researcher chose six participants (i.e., S1, S4, S5, S9, S21, S22) to be interviewed by using convenience sampling in order to get more information regarding students' strategies when solving the problem 
Table 2. Non-routine problems on the test

\section{No Description}

1 Crisbert has a jar of chocolate candies. He gave Jodie $\frac{1}{5}$ portion of the candies. Naira was given $\frac{1}{4}$ of the candies that Jodie has left. Then came Henry. Crisbert gave Henry $\frac{1}{3}$ remaining candies. Then, Yahya was given $\frac{1}{2}$ portion of the candies left in the jar. Finally, there were only fifty candies left in the jar. How many candies were originally in the jar?

(The problem is modified from Manggoes Problem in http://illuminations.nctm.org/)

2 At lunch time, Nickyta went Startbucks to buy coffee for herself and some of her friends. A grande size cup of coffee cost $\$ 4$ and a tall size cup of coffee cost $\$ 3$. She spent $\$ 17$ for 5 cups of coffee. How many cups of coffee did she buy for each size of coffee?

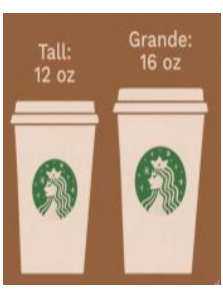

(The problem is modified from Math Olympiad Unleash The Maths Olympian in You!, 2010)

genuinely. Based on Creswell (2012), the goal of convenience sampling is to choose the subjects who are available to be studied and researcher can get deeper understanding about the phenomenon. Besides that, interviewed subjects because they gave the variety data for the findings and give the rich data that could help the researcher to answer the research questions of this study related to common strategies used to get a solution on two non-routine problems.

The researcher collected the data by using a test, classroom observation, interview, and review participants' worksheet. The test contains two non-routine problems (i.e. word problems) about linear equations one variable and simultaneous linear equations two variables. In addition, the problems have different complexity. The non-routine problems on the test are presented in Table 2. The test aimed to identify the common strategies used by the participants when solving the given problems. After creating the instruments, the researcher validated the instruments to the experts who are mathematics lecturers in a private university. Then, the researcher checked the reliability of the instrument by giving the test with similar problems to another $8^{\text {th }}$ grade class. Moreover, the test was given to all twenty $8^{\text {th }}$ grade students, and they were asked to write the steps on how to find the final answer by using their strategy. The researcher instructed the students to use more than one strategy to get a solution on the problems.

After the researcher gave the test, the researcher conducted a semistructured interview with the interviewed subjects. This kind of interview allows flexibility and gives the participants to relax due to the interview (Cohen, Manion, \& Morrison, 2018). In addition, the researcher adopted the interview questions from Lester \& Kroll in 1996 as cited in Kaur (2008), and the interview questions are categorized based on Polya's problem solving phases. There are four phases of problem-solving process, which are understanding the problem, devising a plan, carrying out the plan, and looking back (Polya, 1957). This interview aimed to gain more information related to interviewed subjects' strategies to get a solution on the given problems. The researcher recorded the interview between the researcher and interviewed subjects.

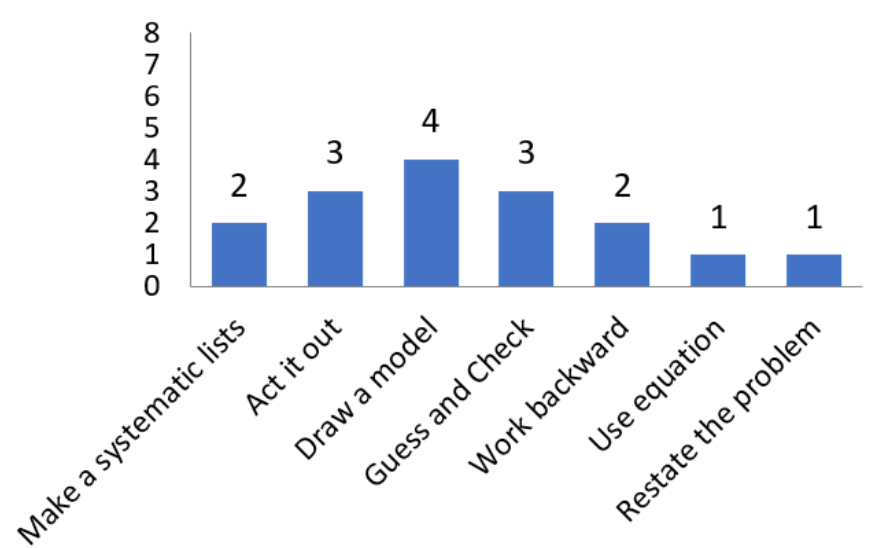

Figure 1. Strategies Used on Problem 1

After conducting the test, the researcher analyzed the data based on the participants' worksheet, observations, and interviews result. Besides, the researcher analyzed the data through coding. Moreover, the researcher identified the strategies used by the participants to get solutions to the problem according to participants' worksheet. Hence, the researcher grouped the participants' worksheet based on the strategies used by participants. There were participants used a systematical list, act it out, draw a model, guess and check, work backwards, using an equation, did not attempt the step (no strategy), and restated the problem.

\section{RESULTS}

Based on participants' worksheet analysis when solving the given problems, participants used seven strategies on problem 1 (i.e. make systematic list, act it out, draw a model, guess and check, work backward, use equation, and restate the problem). In addition, there were also participants who did not performed problem-solving strategies to get a solution on problem 1 . However, all participants used the same strategy to get a solution on problem 2, which is guess and check. In addition, the participants only used one strategy rather whereas the researcher already allowed them to use several strategies to solve the given problems. Then, Figure 1 presents the strategies used by participants in problem 1 .

Based on Figure 2, it indicates that common strategies used by participants to get a solution on problem 1 are draw a model, act it out, and guess and check. Then, since all participants used guess and check to get a solution on problem 2, it indicates that common strategy used on problem 2 is also guess and check. Moreover, although the students already performed problem-solving strategy, but not all participants answer the problem correctly. Then, here are the examples of participants' responses due to the common strategies used on the given problems.

\section{Draw a Model}

Draw a model is a strategy that can be used by problem solvers to illustrate the problem (Kaur, 2008). As explain in Figure 3, 4 out of 20 participants used this strategy to get a solution on problem 1 . Then, it indicates that draw a model is the most strategy used to solve problem 1. In addition, all participants who draw a model are successful in getting the correct answer on problem 1. In Figure 2, S21 drew a model to a get solution to problem 1 . The reason he used this strategy is that 
1. Crisbert has a jar of chocolate candies. He gave Jodie $\frac{1}{5}$ portion of the candies. Naira was given $\frac{1}{1}$ of the candies that Jodie has left. Then came Henry. Crisbert gave Henry $\frac{1}{3}$ remaining candies. Then, Yahya was given $\frac{1}{2}$ portion of the candies left in the jar. Finally, there were only fifty candies left in the jar. How many candies were originally in the jar?

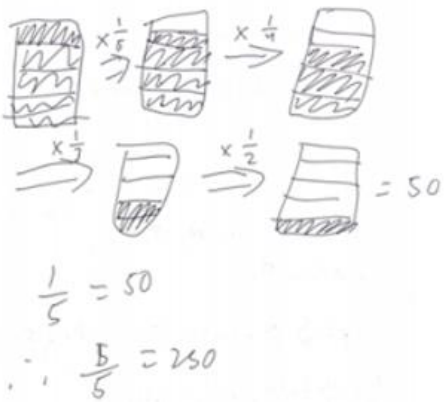

Figure 2. Example of Draw a Model Strategy Used by S21

draw a model is the easiest way to solve problem 1 and it helps him to make a representation of the problem. Then, S21 confirmed in the interview,

S21: "I think that it can make me easier to get the solution. I know that this problem looks like the fraction problem. Then, when I get fraction problem, I usually draw a model because it can help me a lot and it is the easiest way, miss."

Refers to the interview with S21, he can connect the problem with his prior knowledge about fractions and algebra. He also used his experience in using the strategy to get the solution to problem 1.

\section{Act It out}

Based on Figure 4, act it out become one of common strategies used to get a solution on problem 1 . There are 3 out of 20 participants used this strategy but only two participants who used this strategy get the correct answer, another participant failed to get the correct answer.

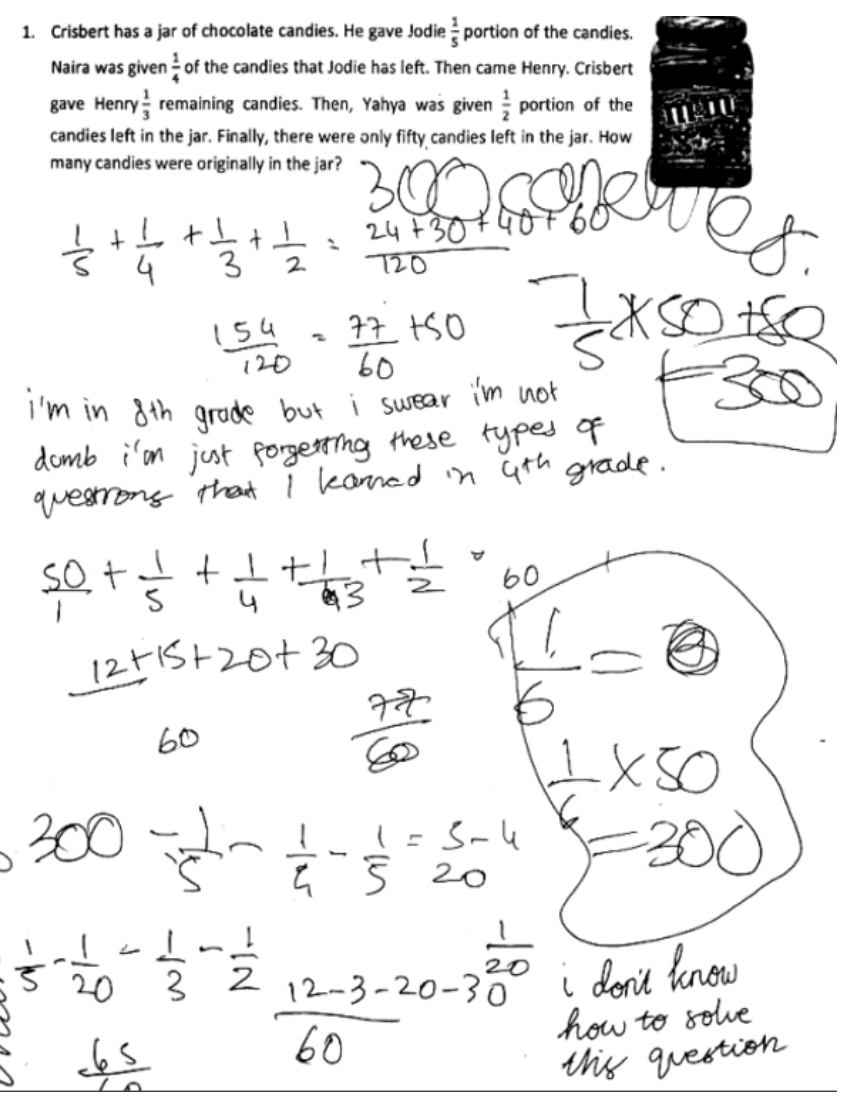

Figure 4. Example of Guess and Check Strategy Used by a participant on Problem 1

Figure 3 is an example of act it out strategy used by S4. Furthermore, in Figure 3, S4 not only performed a problem-solving strategy (i.e., act it out) but also got the correct answer. Then, he used this strategy because when solving this type of problem, he usually used this strategy. It means that he utilizes his previous knowledge and experience to solve

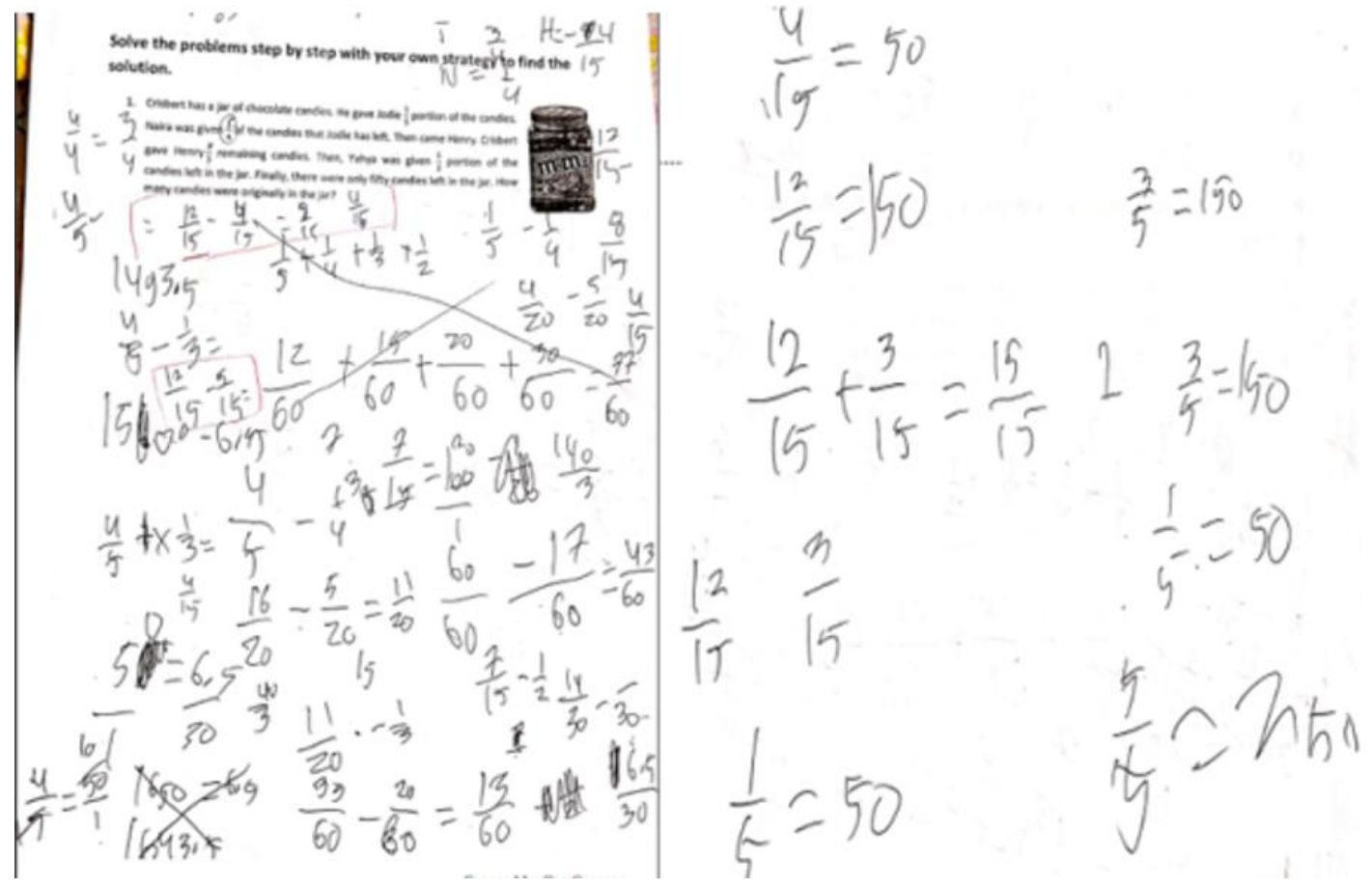

Figure 3. Example of Act It Out Strategy Used by S4 
2. At lunch time, Nickyta went Startbucks to buy coffee for herself and some of her friends. A grande size cup of coffee cost $\$ 4$ and a tall size cup of coffee cost $\$ 3$. She spent $\$ 17$ for 5 cups of coffee. How many cups of coffee did she buy for each size of coffee?
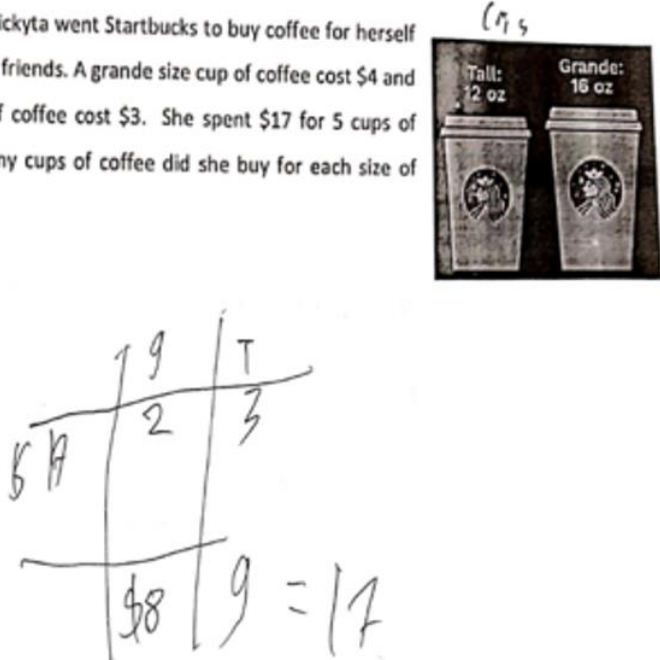

Figure 5. Example of Guess and Check Strategy Used by S4 on Problem

the problem given. His reason already mentioned in the interview as follows

S4: "aku sih kalo dapet soal kayak gini, biasanya pake cara kayak gini, miss"

\section{Guess and Check}

Guess and check is not only common strategy used to get a solution on problem 1 but also common strategy used on problem 2. The participants used this strategy because they thought that it is a simplest way to get a solution on the problems although they did not familiar with the given problems. Based on Figure 1, 3 out of 20 participants used this strategy but all participants who used this strategy got incorrect answer on problem 1 . However, only one participant who got incorrect answer on problem 2 by using guess and check strategy. The rest participants (i.e. 19 students) got the correct answer by using guess and check strategy on problem 2. Figure 4 is an example of participant's response and it shows participant used guess and check strategy to get a solution on problem 1 but she get incorrect answer. Furthermore, Figure 5 shows that 44 performed problem-solving strategy, which is guessing and check and able to get the correct answer. The reason he used this strategy because problem 2 can be solved easily by using guess and check. It is supported with S4's statement in the interview.

S4: "Oke miss, jadi gini miss, di problem ini tuh. Ini mah gampang miss, soalnya kita di sini kan cuman disuruh nyari berapa cups coffee yang ukuran grande sama tall kalo misalkan Nicky belinya 5 kopi. Terus harganya udah ada juga. Jadinya aku pikir ini gampang sih kan ini 5 kopi ya udah tinggal tambah tambahin doanng. Pake guess and check juga ini bisa."

Besides that he is also confident with his answer because he already checked his answer. It is supported, as he mentioned in the interview.

S4: "Udah bener sih miss, karena ketika aku jumlahkan kalo ada 2 grande sama 3 yang tall itu jadi totalnya \$17. Terus itu kan sama hasilnya sama yang dikeluarin sama Nicky buat bayar 5 kopi itu."

\section{Make a Systematic List}

A systematic list is a list produced by listing all the given information based on problems and possibilities systematically. This strategy can be a guideline for the problem solver to attain the solution.
1. Crisbert has a jar of chocolate candies. He gave Jodie $\frac{1}{5}$ portion of the candies. Naira was given $\frac{1}{4}$ of the candies that Jodie has left. Then came Henry. Crisbert gave Henry $\frac{1}{3}$ remaining candles. Then, Yahya was given $\frac{1}{2}$ portion of the candies left in the jar. Finally, there were only fifty candies left in the jar. How many candies were originally in the jar?

\section{Crisbert}

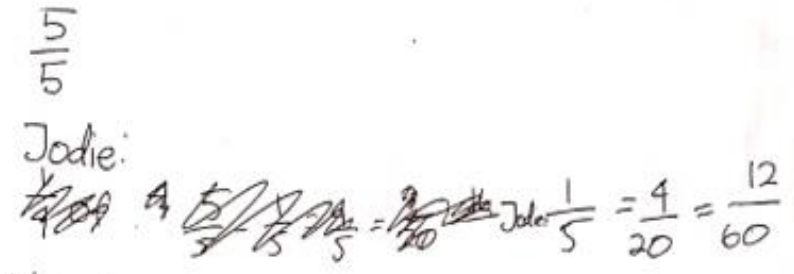

Naira

$\frac{d_{2}}{4} \frac{16}{20}-\frac{5}{20}=\frac{11}{20} \quad$ Naira $=\frac{5}{20}=\frac{15}{60}$

Henry.

Remaining $=\frac{11}{20}$

$$
\begin{aligned}
\text { Henry } & =\frac{11}{20}-\frac{1}{3} \\
& =\frac{33}{60}-\frac{20}{60} \\
& =\frac{13}{60}
\end{aligned}
$$$$
\frac{12}{60}+\frac{15}{60}+\frac{413}{60}
$$

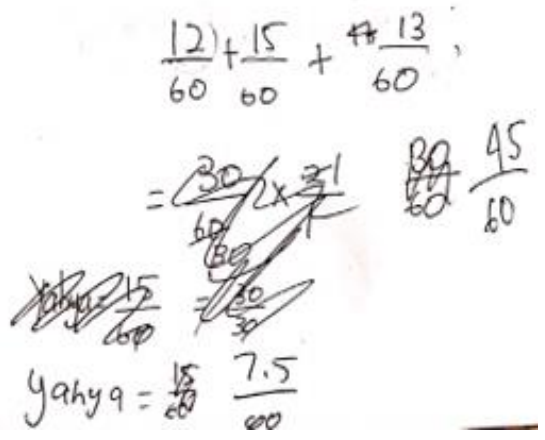

$\frac{15}{60}=50$

$\frac{30}{80}+\frac{15}{60}=\frac{45}{60}$

60

$\frac{15}{60}=$

ans $=900$

Figure 6. Example of Make a Systematic List Strategy Used by S1

Based on Figure 1, two participants of this study used this strategy to get a solution on problem 1. However, they got incorrect answer when using this strategy. Figure 6 is example of S1's responses that shows he made a systematic list. Then, in Figure 6, S1 already tried to perform problem-solving strategy (i.e. make a systematic list) but he failed to get the correct answer. It is because he did miscalculation in adding the fractions with a common denominator. The example of his miscalculation is $\frac{12}{60}+\frac{15}{60}+\frac{13}{60}=\frac{45}{60}$. This miscalculation can lead to an incorrect answer. 


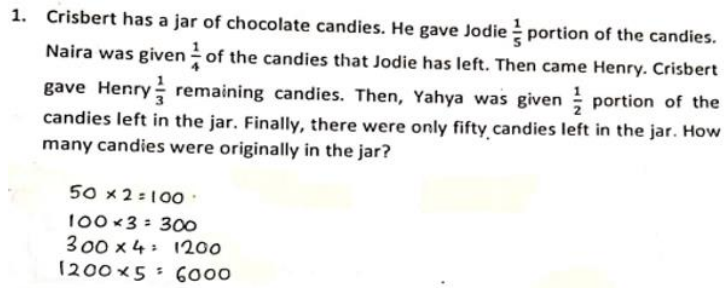

Figure 7. Example of Work Backward Strategy Used By S9 on Problem 1

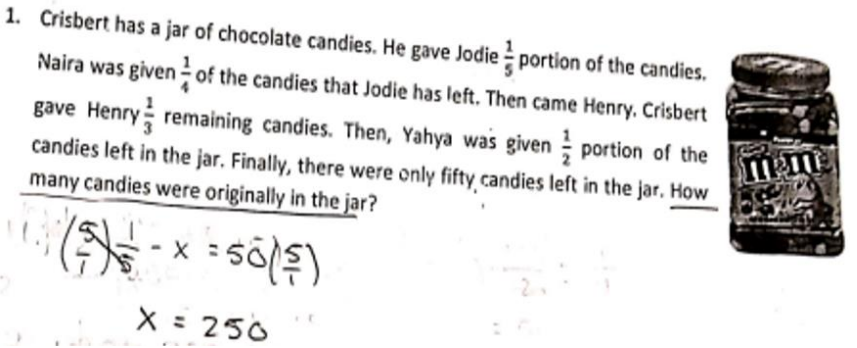

Figure 8. Example of Use Equation Strategy Used By S22 on Problem 1

\section{Work Backward}

In work backward strategy, problem solver starts to solve the problem from an endpoint of a condition to where it is happening. Then, based on Figure 1, only one participant, which is S9 who used this strategy to get a solution on problem 1. Unfortunately, she got incorrect answer when solving problem 1 because she made incorrect formulation on step two in finding the numbers of candies. Figure 7 is example of S9's response on problem 1. The reason S9 used this strategy is that she only knew a backward strategy to solve the given problem. It is mentioned in the interview result as follows

S9: "Because I did not have any idea, only this. And I thought that it is one of the only methods possible."

\section{Use Equation}

Based on the participants' worksheet, there is only one participant (i.e. S22) used equation to get a solution on problem 1. S22 not only performed problem-solving strategy, which is use equation but also get the correct answer. The example of S22's works on problem 1 is shown in Figure 8. Then, the reason why she used this strategy it can be seen from the interview part as follows

S22: “...because I only know this strategy. Then, only this strategy that come up in my mine at that time."

\section{Restate the Problem}

This strategy sometimes can help define the problem. Then, restating the problem into the simplest one can help problem solver to

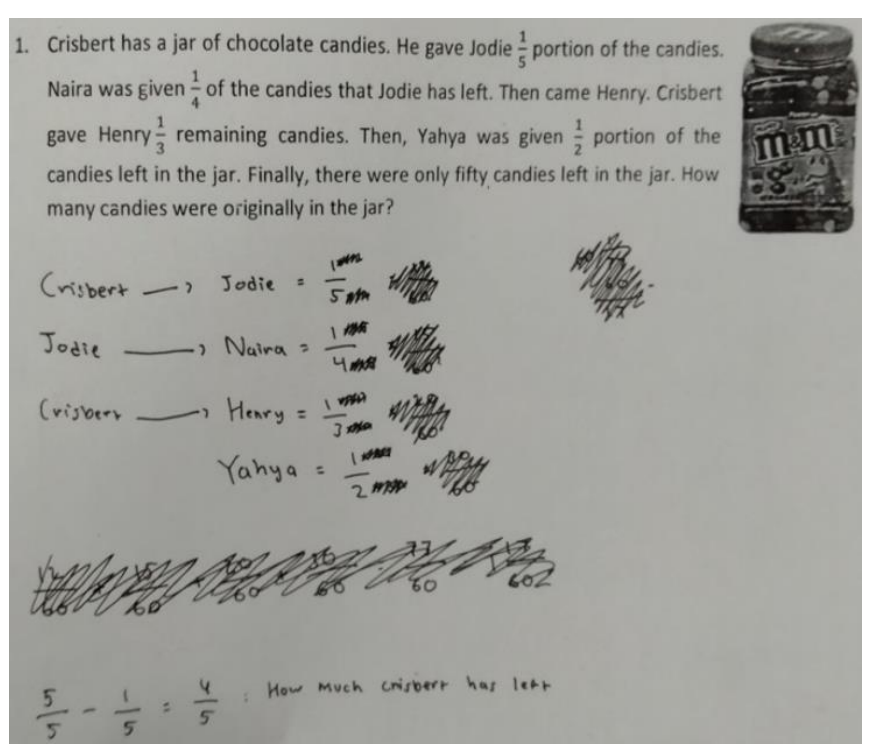

Figure 9. Example of Restate the Problem Strategy

understand and solve the problem. Moreover, this strategy was found when the participant solve problem 1 and there was only one participant who used this strategy. Unfortunately, he only restated the problem without continuing his work until get the answer. Figure 9 shows a participant used this strategy.

Referring to the findings, the participants have not familiar with problem 1 and rarely solve this kind of the problem, thus the common strategies used by the participants were various. On the other hand, since the participants already familiar with problem 2 and they have more experience in solving this kind of problem, they solved the problem confidently with guess and check strategy. The reason is that they thought that when they solved this kind of problem with guess and check they usually get the correct answer, so that they used this strategy to solve problem 2. It is supported by the subjects that mentioned they already familiar with the problem 2 and usually use guess and check to solve the problem 2 .

S21: "Emmm.. I used this strategy because I ever solve this kind of problems, then when I solve it by using guess and check, I got the answer. And when seeing this problem, I usually find this kind of problem."

S22: "I just used the guess and check method, miss. Cause the I learned that on my own school. We have found this problem in the class. I think that I ever found and solve problem 2 several times with guess and check. And I got the correct answer."

S5: "mmm, I found this kind of problem in the classroom and in the textbook. And I have tried to solve the problem by guessing the answer and I got the answer, miss. Then, I usually use guess and check, if I find this kind of problem."

According to the interview with the teacher in school, S21 is categorized as a student who has high performance in mathematics. Then, S22 is one of students who has average performance and S5 is one of students who has low performance in mathematics. Although each of them has different performance level in mathematics but they used the same strategy for problem 2 based on what they already used previously. The reason is that they already familiar with problem 2 . Thus, it is indicates that by giving non-routine problems to the 
participants, it promotes various problem-solving strategies used by the participants.

\section{DISCUSSION}

According to the findings, it indicates that most of the participants already tried to perform problem-solving strategies even though some participants were unable to get the correct answers. Then, the participants of the study used different strategies to get a solution to the given problems based on their prior experience, knowledge, and intuition in solving the problems. Furthermore, the result shows that there were three common strategies used by participants to get solutions on problem 1 (i.e. draw a model, act it out, and guess and check) and used guess and check to get a solution on problem 2 .

These findings showed that participants could use different strategies to solve non-routine problems. Then, Saygily (2017) and Barake (2015) conducted the study and resulting in the same findings as this study. Although the researcher allowed the participants to use more than one strategy to solve the given problem, some participants only used one strategy to solve each problem. Then, this situation also happened in Saygily's study when the participants solved the given problems. They only used one solution for each problem.

Interestingly, the researcher found that there were various strategies used by participants in problem 1 , and there were various solutions produced by the participants. Also, 13 out of 20 participants got an incorrect answer on problem 1. It might be happening because based on their response; they did not feel familiar with problem 1 and rarely solve the problem like problem 1 . Thus, it could make it difficult to solve problem 1 . On the other hand, participants used the same strategy to solve problem 2, it was resulting in the same answer, and only one participant get an incorrect answer. It indicates that participants can solve problem two successfully because 1) they ever solve this kind of problem with the same strategies, 2) problem 2 is considered as a problem with low complexity if it is referred to problem 1 , which is more complicated rather than problem 2.

Regarding those conditions, where the students still unfamiliar with solving non-routine problems, teachers in school need to find ways to develop students' problem-solving ability. Based on Boesen et al. (2010) and Nancarrow (2004) as cited in Saygili's study, teachers in school need to bring or involve non-routine problems in the classroom. The reason is that by giving non-routine problems, it gives the students opportunity to use any strategies and to tell the strategies on how to get the solutions on the problem. Besides that by giving non-routine problems, the students can get the opportunity to utilize their experience, prior knowledge to solve the problem in uncommon strategy. Then, it might encourage students to use various strategies and more than one strategy to get a solution to the problem.

Based on Singh et al.'s study (2018), implementation of problemsolving strategy in the classroom gave good influence towards mathematical thinking. Then, as mentioned by Polya, the goal of the strategy is to learn the method and rules that can supports students to arrive with various strategies when solving the problems. Singh also argued that the reason why the implementation of problem-solving strategy in this study was succeeded because Singh et al. build learning experiences that encourage students to provoke the condition of the problem transmits the generation of important ideas of mathematics and use their knowledge of learning problem-solving strategies to solve the given problems. Thus, implementing or involving problem-solving strategies in the classroom is recommended because it gives many advantages, particularly for the students and teachers in school.

\section{CONCLUSION}

According to the findings, the researcher concludes that there are three common strategies used by participants to problem 1 (i.e., draw a model, act it out, and guess and check) and one common strategy used (i.e. guess and check) to get a solution on problem 2. The participants used those kinds of strategy because they had ever solved this similar problem (i.e. problem 2) and used the same strategy to get the solution to the problem. Based on the findings, which is students have not familiarized with the non-routine problems and problem-solving strategy, thus, teachers need involve or give non-routine problems to the students that can promote multiple problem-solving strategies when solving mathematical problems. Moreover, this study also has a limitation in terms of the duration of the test. Therefore, further study need to extend the duration on the test.

\section{REFERENCES}

Baraké, F., El-Rouadi, N., \& Musharrafieh, J. (2015). Problem Solving at the Middle School Level: A Comparison of Different Strategies. Journal of Education and Learning, 4(3), 62-70. https://doi.org/10.5539/jel.v4n3p62

Cai, J., \& Lester, F. (2010). Why is Teaching with Problem Solving Important to Student Learning? NCTM. Retrieved from https://www.nctm.org/uploadedFiles/Research_and_Advocacy/r esearch_brief_and_clips/Research_brief_14__Problem_Solving.pdf

CIE. (2016). IGCSE Mathematics Syllabus 0580. (March).

Cohen, L., Manion, L., \& Morrison, K. (2018). Research Methods in Education (8th ed.). New York: Routledge. https://doi.org/10.4324/ 9781315456539

Creswell, J. W. (2012). Educational Research: Planning, COnducting, and Evaluating Quantitative and Qualitative Research (4th ed.). New York: Pearson College Division.

Fraenkel, J. R., \& Wallen, N. E. (2008). How to Design and Evaluate Research In Education (7th ed.). New York: McGraw-Hill Higher Education.

Kaur, Beriderjeet. (2008). Kaur (2008). Problem Solving in the Mathematics Classroom (Secondary). Singapore: National Institute of Education.

Kurniati, D., \& Annizar, A. M. (2017). The analysis of students' cognitive problem solving skill in solving PISA standard-based test item. Advanced Science Letters, 23(2), 776-780. https://doi.org/10.1166/asl.2017.7466

Lambert, V. A., \& Lambert, C. E. (2012). Editorial: Qualitative Descriptive Research: An Acceptable Design. Pacific Rim International Journal of Nursing Research, 16(4), 255-256.

Nurkaeti, N. (2018). Polya'S Strategy: an Analysis of Mathematical Problem Solving Difficulty in 5Th Grade Elementary School. EduHumaniora / Jurnal Pendidikan Dasar Kampus Cibiru, 10(2), 140. https://doi.org/10.17509/eh.v10i2.10868 
OECD. (2016). Country note - results from PISA 2015: Indonesia. Oecd, 1-8. Retrieved from https://www.oecd.org/pisa/PISA-2015Indonesia.pdf

Saygilı, S. (2017). Examining the Problem Solving Skills and The Strategies Used by High School Students in Solving Non-routine Problems. E-International Journal of Educational Research, 8(2), 91114. Retrived from http://static.dergipark.org.tr/articledownload/701a/4b75/8667/59adca7d2719f.pdf
Singh, P., Teoh, S. H., Cheong, T. H., Md Rasid, N. S., Kor, L. K., \& Md Nasir, N. A. (2018). The Use of Problem-Solving Heuristics Approach in Enhancing STEM Students Development of Mathematical Thinking. International Electronic Journal of Mathematics Education, 13(3), 289-303. https://doi.org/10.12973/ iejme/3921 